\title{
Exorcism and Justified Belief in Demons
}

\section{Marcus William Hunt}

Aвstract The paper offers a three-premise argument that a person with first-hand experience of possession and exorcism, such as an exorcist, can have a justified belief in the existence of demons. (1) "Exorcism involves a process by which the exorcist comes to believe that testimony is offered by a demon." Cited for (1) are the Gospels, the Roman Ritual, some modern cases of exorcism, and exorcism practices in non-Christian contexts. (2) "If defeaters are absent, the exorcist may treat as reliable the process by which he comes to believe that testimony is offered by a demon." For (2) a case is offered that we have a reliable ability to identify when testimony is being offered and when it is being offered by particular types of agents, what is termed testifier-identification. (3) "In many cases of exorcism, defeaters are absent." An inductive case is given for (3) by responding to possible defeaters, including several suggested recently by David Kyle Johnson. Therefore, in many cases of exorcism the exorcist may treat as reliable the processes by which he comes to believe that testimony is offered by a demon, and so can have a justified belief in the existence of demons.

KEYwords demonic possession; exorcism; reliabilism; social epistemology; testimony

Marcus William Hunt, Tulane University 105 Newcomb Hall, 1229 Broadway, New Orleans, Louisiana, 70118, USA
(D) $0000-0001-6858-1903$ 


\section{INTRODUCTION ${ }^{1}$}

It has been argued by David Kyle Johnson that the existence of demons is not the best abductive explanation for any set of phenomena, whether the phenomena in question are stories of possession and exorcism or first-hand experiences of what one takes to be possession and exorcism. Hence, Johnson concludes that "it is impossible for belief in the existence of demons to be justified" (Johnson 2017, 176). I suggest an alternative route to justified belief in demons for the person with first-hand experience of possession and exorcism, such as an exorcist, that is reliabilist rather than abductive. Here is the structure of the argument:

(1) Exorcism involves a process by which the exorcist comes to believe that testimony is offered by a demon.

(2) If defeaters are absent, the exorcist may treat as reliable the process by which he comes to believe that testimony is offered by a demon.

(3) In many cases of exorcism, defeaters are absent.

Therefore, in many cases of exorcism, the exorcist may treat as reliable the process by which he comes to believe that testimony is offered by a demon. ${ }^{2}$

So, such an exorcist may believe that demons exist. Cited in support of (1) are the Gospels, the Roman Ritual, some modern cases of exorcism, and exorcism practices in non-Christian contexts. These show that exorcism paradigmatically (if not strictly necessarily) involves a process by which the exorcist comes to believe that testimony is offered by a demon. Regarding (2), note that coming to believe that testimony is offered by a certain type of agent is distinct from coming to believe the content of an agent's testimony. Given that demons are evil it would be foolish to readily believe the content of their testimony-demons are likely to lie and mislead and they are not capable of sustaining the norms of trust and assurance that (some argue) underpin the distinctive epistemic value of testimony (Shieber 2015,

1. The author thanks Jordan Neidlinger and Geoffrey Weiss for their helpful comments on earlier versions of this paper.

2. Although the argument is framed in reliabilist and externalist terms, the argument can be recast in phenomenal conservative and internalist terms for those who prefer:

(1) In exorcism it seems to the exorcist that testimony is offered to him by a demon.

(2) In the absence of defeaters, if it seems to the exorcist that testimony is offered to him by a demon, the exorcist has justification for believing that testimony is offered to him by a demon.

(3) In many cases of exorcism, defeaters are absent.

Therefore, in many cases of exorcism, the exorcist has justification for believing that testimony is offered to him by a demon. 
148-75). I provide an inductive case for thinking that we have a reliable ability to identify when testimony is being offered and when it is being offered by particular types of agents, what I term testifier-identification. I then argue for (3) by examining and responding to possible defeaters, including Johnson's claim that the existence of demons is not the best explanation for any set of phenomena.

\section{EXORCISM INVOLVES A PROCESS BY WHICH THE EXORCIST COMES TO BELIEVE THAT TESTIMONY IS OFFERED BY A DEMON}

\section{The Gospels}

At least seven exorcisms are described in the Gospels. One is the exorcism in Gerasene:

When he saw Jesus, he fell down before him and shouted at the top of his voice, "What have you to do with me, Jesus, Son of the Most High God? I beg you, do not torment me"-for Jesus had commanded the unclean spirit to come out of the man. (For many times it had seized him; he was kept under guard and bound with chains and shackles, but he would break the bonds and be driven by the demon into the wilds.) Jesus then asked him, "What is your name?" He said, "Legion"; for many demons had entered him. They begged him not to order them to go back into the abyss. (Luke 8:28-31. NIV)

Note that during the exorcism the demons address Jesus, Jesus addresses a question to them, and they provide an answer. An exchange of testimony between demons and an exorcist is reported.

\section{The Roman Ritual}

The Roman Catholic Church's rite of exorcism, as outlined in the Roman Ritual, specifies that the demon being exorcised is to be addressed with imperatives:

I command you, unclean spirit... I cast you out, unclean spirit...I adjure you, ancient serpent... Depart, then, transgressor... (Weller 2017, Pt.13, Ch.2, S.2)

Likewise, the Roman Ritual advises that the exorcist address questions to the demon being exorcised and specifies the nature of the questions, in the hope that the relevant testimony will be forthcoming from the demon: 
necessary questions are, for example: the number and name of the spirits inhabiting the patient, the time when they entered into him, the cause thereof, and the like (Weller 2017, Pt.13, Ch.1, S.15)

\section{Modern cases}

Fr. Gabriel Amorth noted often being directly addressed by demons during exorcisms:

In cases of strong possessions the demon might speak voluntarily to discourage the exorcist. Many times I was told, "You cannot do anything against me!" "This is my home; I am happy here, and here I will stay." "You are wasting your time." Other times I was threatened: "I will eat your heart!" "Tonight I will frighten you so much that you will not be able to close your eyes." "I will come into your bed like a snake." "I will throw you out of bed." (Amorth 1990, 96)

Again, the anthropologist Andrea De Antoni reports on an exorcism that he helped with:

Several minutes after the start of the psalm, the devil started screaming "enough!" or "go away!" At times during the psalm, more often during the exorcism, Father Vinicio would stop to engage in conversation with it. He would provoke or mock the devil, remarking his own strength and its weak position... sometimes, it provoked back with sentences such as "I will never give her to you. Never! NEVER!" (growling), or "She was abandoned and I got her. She is mine. Mine. MINE!” (growling)... The devil addressed us helpers, too. Once, while struggling to break free, it asked "Don't you have anything better to do on a Saturday morning?"-displaying a certain sense of humor. (De Antoni 2017, 150-1)

\section{Exorcism practices in non-Christian contexts}

Belief in demons, possession, and exorcism, are cross-cultural. In many cultures rites of exorcism also involve direct address between the exorcist and the demon-this is true of the Islamic context (Guthrie, Abraham, and Nawaz 2016; Utz 2012, 20), the Hindu context (Dwyer 1999, 113, 118), and the Tibetan Buddhist context (Lopez 1996, 226-7). Textual evidence from further cultures has proved difficult to find.

\section{Significance}

Exorcism paradigmatically involves a process by which the exorcist comes to believe that testimony is offered by a demon. Although the term 
"conversation" might have an odd connotation, it seems that the exorcist will regard himself as being in conversation with a demon during some phases of the exorcism. Exorcism therefore involves interpersonal experiences which are phenomenologically distinct from experiences of natural phenomena. In exorcism, the exorcist seems to have not simply some things to observe and to explain but a someone to address and be addressed by, to tell and be told by, to ask and to answer.

\section{IF DEFEATERS ARE ABSENT, THE EXORCIST MAY TREAT}

\section{AS RELIABLE THE PROCESS BY WHICH HE COMES TO BELIEVE} THAT TESTIMONY IS OFFERED BY A DEMON

The philosophical literature on testimony focuses heavily on questions of the epistemic value of testimony, such as whether testimony can be presumptively treated as a reliable epistemic source or whether we must possess inductive evidence that testimony is reliable, whether testimony is a basic epistemic source or whether testimony is ultimately reducible to other epistemic sources (Shieber 2015). We are instead concerned with whether the exorcist can treat as reliable the process by which he comes to believe that testimony is being offered at all, and by which he comes to believe that testimony is being offered by a certain type of agent. In most day-to-day cases it is obvious when testimony is being offered and by whom it is being offered, so it is unsurprising that these issues are underexamined in the philosophical literature. With respect to exorcism one might reasonably think that in the types of cases related above we have (i) no testimony at all but mere utterance (akin to utterance during high fever), or (ii) testimony from the patient, or (iii) testimony from an "alter" (Gillig 2009), a "personality" distinct from that of the patient but a "personality" of a non-demonic nature, a symptom of a mental illness like Dissociative Identity Disorder.

Some may take the position that there is no need to provide evidence that the exorcist's process of coming to believe that testimony is offered by a demon is reliable. Rather, they may take the position that the argumentative burden here is entirely on the debunker to show that the exorcist's process is unreliable. By analogy, some may take the position that when they come to believe a moral claim because it seems true to them, they have no argumentative burden of offering evidence for the reliability of such seemings before they may treat such seemings as reliable.

Others may insist that we need to provide at least some evidence that the exorcist's process of coming to believe that testimony is offered by a demon is in fact reliable. One way of providing evidence that the exorcist's process 
of coming to believe that testimony is offered by a demon is reliable would be to ascertain independent-knowledge (Shafer-Landau 2012) of whether in fact a demon did offer testimony in a token case and then check the exorcist's beliefs against this independent-knowledge. As an example, one might check the result of one's mathematical working against the mathematical working of a mathematics professor or a calculator. However, it seems all but impossible that we can ascertain independent-knowledge of whether a demon offered testimony in a token case-appeal to an "expert" exorcist will appear circular to the sceptic, and there is no equivalent to a calculator in this domain.

Let's call the process that leads to the exorcist's belief that they are being addressed by a demon testifier-identification. Testifier-identification is the process by which one identifies that testimony is being given, weighing against alternative (i), and identifies by what type of agent testimony is being given, weighing against alternatives (ii-iii). Testifier-identification is a process that operates in a wide variety of less esoteric cases, as I will illustrate shortly. My suggestion is that if we can provide evidence that testifier-identification is a reliable process in that wide variety of less esoteric cases, then we will have provided some evidence that the exorcist's process of coming to believe that testimony is offered by a demon is in fact reliable, even though we cannot provide independent-knowledge for given tokens of apparent demonic testimony. For example, if on one occasion you are sat alone in your office and hear an unfamiliar buzzing sound it will probably be the case that you cannot (practically speaking) provide independent-knowledge that something was making a buzzing sound (since no one else is around and you are not recording with microphones)-but you can take steps to check whether your hearing is reliable (visiting an audiologist). Most of the token experiences that fill up everyday life are ones for which we cannot (practically speaking) provide much independent-knowledge, but this is not so troubling if the reliability of the underlying processes that give rise to them are checkable.

\section{That testimony is being offered}

I offer some fictional scenarios in which testifier-identification is going on, which hopefully the reader will find to match with some of their own experiences. Consider the following scenario:

You receive the following text message on your phone from your spouse: "Are we still going to be able to make it to the game tonight as you know we have a few things to download?" Initially you are puzzled as you have no recollection 
that you were supposed to go to a game tonight and you have no clue what things it is that you were supposed to download. As you are puzzling, you receive another text message from your spouse: "Don't forget about the human race and the rest of them and I will deliver the product." There is a change in how you see the text messages-it seems to you that your spouse's phone must be malfunctioning, that the autocomplete on your spouse's phone is encoding nonsense as the phone is "open" and in their pocket. Later your spouse arrives home and they confirm this latter understanding of the text messages.

In this scenario there is a phenomenologically noticeable gestalt-switch from taking the text messages as testimony offered by your spouse to taking the text messages as non-testimonial in nature. Such cases bring into phenomenological relief our process of testifier-identification. In this case, you receive independent-knowledge that your process of testifier-identification produced a false belief in the first instance and a true belief in the second instance. Similar examples can be adduced in the auditory mode:

You are sat in a spooky old house late at night. You hear knocking noises, the knocks having brief but varying temporal gaps between them. You take the knocking noises to be non-testimonial in nature, you take them to be a rattling pipe. There is then a change in how you hear the knocks-they mean "Ghost" in "knock code" (also known as tap code). Shortly after, your prankster friend comes into the room and confirms that he knocked "Ghost" in knock code on the wall of an adjoining room.

\section{That testimony is being offered by a certain type of agent}

We can also adduce examples of gestalt switches in which testifier-identification identifies a type of agent by which testimony is being offered; when we switch between hearing testimony as from a child or an adult, a robot or human, an expert or non-expert, of an agent inhabiting a particular social role, or of a particular moral character.

In the year 2025, your telephone rings. You answer it and hear an artificial intelligence's voice say "Hello Mr. Mainwaring, this is Jay from the Bank of Acadiana-we have been trying to reach you concerning your unpaid overdraft fees..." You start shouting abuse at the AI. It then says "I've had enough of this job" and starts crying. You hear the voice as that of a real human operator and you profusely apologize. You later look online and read that it is a new policy of the Bank of Acadiana that debt-collection calls are only made by human operators. 
You are engrossed in writing your dissertation. From the next room you hear your father ask "Hey, I need a ride to the bus station..." You are confused because he has never made a request of such a kind before. You respond "Sure, but where are you going?" He says "I've got to get back home to Lafayette, it was nice to see you this weekend though." Midway through the second sentence you realize that you are being offered testimony by your uncle.

You are loitering outside a department store in a large city. A friendly man comes out of the department store and begins to make small talk with you: remarking on the weather, asking you how your day is going. You then notice a charity's logo on his jacket-you now hear him as a chugger (a charity-mugger) rather than hearing him as a friendly man.

In each case here we have a gestalt-switch. Different things seem to set off these gestalt-switches; a sensory experience, the content of the testimony, a process of reflection, a memory. This shows that testifier-identification is a complex process drawing on many other processes, that many lower-level (re)presentations help us in forming a (re)presentation of what type of agent is offering testimony, and indicates that the latter sort of (re)presentation is not reducible to any particular such (re)presentation of the former sort. ${ }^{3}$

Is testifier-identification a reliable process? So far as I am aware, there have been no controlled trials of people's ability to identify different types of agent. We might imagine a trial analogous to a Turing Test in which via a text-based conversation people had to identify whether they were receiving testimony from an adult or a child, a man or a woman, etc. So far as I am aware, no such test has been conducted. Moreover, such a test would have a vastly poorer informational input than what our process of testifier-identification has access to in real-life. The positive evidence for the reliability of our process of testifier-identification must therefore be drawn from real-life anecdotal experiences. The key observation is that gestalt-switches of the sort offered above are relatively rare. For the most part, our process of testifier-identification gives the right result and is highly consilient with our sensory, reflective, and mnemonic processes. It is a rare but striking experience for testifier-identification to give the

3. For the purposes of this paper I suggest simply that testifier-identification, whatever type of mental states it involves, leads to and justifies the exorcist's belief that he is addressed by a demon. A number of recent papers within the philosophy of perception suggest that many high-level properties such as moral properties, intentions, mental states, and emotions, can be presented in perceptual experience (Helton 2016). Plausibly, the arguments made in these papers can be extended to testimony, agents, and agent-types. 
wrong result, e.g. to hear testimony as that of an adult but then to realize that one is conversing with a child. The positive evidence for the reliability of testifier-identification is therefore limited but real enough.

\section{Alternative routes to belief in demons from exorcism}

I note that testifier-identification is probably not the only process by which possession and exorcism phenomena could lead an exorcist to believe that demons exist. As the Roman Ritual notes, the exorcist should look for signs such as:

ability to speak with some facility in a strange tongue or to understand it when spoken by another; the faculty of divulging future and hidden events; display of powers which are beyond the subject's age and natural condition (Weller 2017, Pt.13, Ch.1, S.3)

Presumably, when these events occur the exorcist makes the inference that they are best explained by the existence of demons. Or again, Malachi Martin claimed that the exorcist may come to believe that a demon is present due to having a strong impression or feeling (completely nonsensory, unaccompanied by any visual or auditory phenomena) of the presence of a demon (Martin 1992).

However, it seems that a process like "inferring from apparently supernatural abilities" is not the type of process the reliability of which we can check by looking to its use in less controversial cases. Again, a process like "having an impression/feeling that some type of agent is present," although checkable, is of questionable reliability, e.g. given the apparent failure to reproduce Rupert Sheldrake's claim that the sense of being stared at reliably indicates that one is being stared at (Lobach and Bierman 2004).

\section{IN MANY CASES OF EXORCISM, DEFEATERS ARE ABSENT}

It is difficult to completely foreclose the possibility of defeaters for an exorcist's belief that testimony is offered by a demon. I make an inductive argument for premise (3) by examining plausible apparent defeaters that have been or might be suggested and showing that they are not in fact defeaters.

(a) The best explanation of possession and exorcism phenomena is naturalistic. This provides independent-knowledge that the process by which the exorcist comes to believe that testimony is being offered by a demon is unreliable, or that the process goes wrong in tokens of that type. 
The first sentence of this objection is Johnson's claim, and the second sentence relates his claim to the present reliabilist argument. My first response is to deny that the best explanation for possession and exorcism phenomena is naturalistic. Johnson suggests that stories of possession and exorcism can be explained as cases of fraud and mental illness, instead of by the explanation that demons exist. Johnson takes this to mean that there are several empirically adequate explanations for stories of these types. Johnson applies the same claim to the exorcist's own first-hand experiences. Given that each of these explanations is empirically adequate, Johnson suggests that to find out which is the best explanation we need to evaluate the competing explanations in terms of their theoretical virtues. Johnson offers four familiar theoretical virtues:

Fruitfulness: To be fruitful, $\mathrm{n}$ hypothesis must make predictions beyond what we already know and get those predictions right.

Scope: ...Does it explain a wide variety of phenomenon?

Parsimony: ... requiring the existence of additional, or unproven, entities violates parsimony.

Conservatism: To be conservative, $\mathrm{n}$ hypothesis must align with things that we already know are true (Johnson 2017, 177)

Johnson suggests that the demonic explanation is less fruitful because it predicts that "one should not find evidence of lying, trickery, or mental illness" (Johnson 2017, 182) whereas in fact many apparent cases of possession and exorcism turn out to be cases of fraud or mental illness. Again, these sorts of naturalistic explanations will have a wider scope because they "can not only explain stories of demon activity but also stories of ghosts, alien abductions, UFO sightings, Bigfoot, and any other supposed paranormal happening" (Johnson 2017, 182). Again, according to Johnson the demonic explanation is wildly unparsimonious and unconservative because it "hypothesizes the existence of an entire spiritual realm" (Johnson 2017, 182), whereas since we already know that fraud and mental illness occur, these naturalistic explanations are parsimonious and conservative.

I agree with Johnson that there are several empirically adequate explanations for stories of possession and exorcism, and for the exorcist's own first-hand experiences, and that we should adjudicate between empirically adequate explanations by means of theoretical virtues such as the ones 
which he identifies. However, Johnson's argument is ineffective because it is only on the assumption of a naturalistic worldview that the demonic explanation is theoretically unvirtuous. If one begins with a traditional Christian worldview the demonic explanation will not be theoretically unvirtuous. With respect to conservatism and parsimony, the traditional Christian who posits demons as an explanation for possession and exorcism will not be positing types of entities that do not already appear in his or her ontology (and so are not objectionably "queer") but rather will be making use of entities already posited. ${ }^{4}$ Similarly, with respect to scope, the traditional Christian who posits demons as an explanation for exorcism might also posit them as an explanation for the occurrence of much natural and moral evil (Dunnington 2018; Boyd 2001), as well as possibly some of the paranormal happenings that Johnson mentions (Rogo 1974). Lastly, it is doubtful that the naturalistic explanations are more fruitful. Both naturalists and supporters of the demonic explanation are well-appraised of the fact that Johnson mentions; that many cases of apparent possession turn out to be cases of fraud or mental illness. The demonic explanation does not predict otherwise, any more than the theory that there are geniuses predicts that there will not be many apparent geniuses who turn out to be frauds or mentally ill. Note that the Roman Ritual itself advises the exorcist to distinguish possession from natural illness (Weller 2017, Pt.13, Ch.1, S.3), and that in both the ancient and medieval world natural illness as an explanation of strange behavior was distinguished from possession (Kroll and Bachrach 1984). Neither explanation is fruitful in the sense Johnson discusses, that is, with respect to predicting whether future token cases of apparent possession will turn out to be cases of fraud or mental illness or not. That exorcism phenomena as a type occur at all is predicted by the

4. The idea that there are spiritual beings other than God is a core aspect of traditional Christian belief, rather than an ad hoc addition. Biblical affirmations abound, and philosophically Thomas Aquinas suggests in his Treatise on the Angels Summa Theologiae that we should find every link in the great chain of being to be occupied:

"He [God] brought things into being in order that His goodness might be communicated to creatures, and be represented by them; and because His goodness could not be adequately represented by one creature alone, He produced many and diverse creatures, that what was wanting to one in the representation of the divine goodness might be supplied by another" (ST I.47.1).

"There must be some incorporeal creatures. For what is principally intended by God in creatures is good, and this consists in assimilation to God Himself. And the perfect assimilation of an effect to a cause is accomplished when the effect imitates the cause according to that whereby the cause produces the effect; as heat makes heat. Now, God produces the creature by His intellect and will. Hence the perfection of the universe requires that there should be intellectual creatures" (ST I.50.1). 
claim that demons exist, but not by naturalism (though naturalism is able, with minor theoretical complications, able to offer empirically adequate theories of the occurrence of this type of phenomena).

Here is a second response to this objection, consistent with the one just offered. It seems that we can concede that some naturalistic explanation is the best explanation of possession and exorcism phenomena without this acting as a defeater for the exorcist's belief that he is offered testimony by a demon. When we have independent-knowledge we can check and see that some process is unreliable either in general or in a token case. Yet, plausibly, that the best explanation of some phenomena does not involve entity $\mathrm{X}$ is not sufficient to constitute a defeater of a belief that $\mathrm{X}$ was present. There is a gulf between having independent-knowledge and merely having a best explanation, especially where the best explanation is only better on the grounds of certain theoretical virtues. By analogy, suppose that you live in rural Ireland and that there have recently been three burglaries in your ordinarily crime-free village. In each case the burglar was identified as having an Australian accent when confronted by the householders. You then encounter a burglar in your house, and it seems to you that they have an American accent. The explanation that the burglar in your house also had an Australian accent which you misheard perhaps has a wider scope, is more parsimonious, and more conservative, than the explanation that there are two international burglars on the loose in your village. Nevertheless, it seems reasonable for you to continue believing that the burglar in your house had an American accent.

(b) "Personal experience is notoriously unreliable; our senses are easily fooled and concoct false sensations when presented with vague stimuli." (Johnson 2017, 177)

Supposing that the objection is correct, it seems to get the wrong extension in that it applies to much more than exorcism. Moreover, the objection is not correct because it is overstated. It is true that our senses do go wrong in many ways at many margins, and that these errors will arise in some experiences of possession and exorcism. But our processes do not have to be infallible to be reliable-a point which applies to the process of testifier-identification as much as sensory processes.

(c) "The faculties of those involved could hardly be said to be reliable at the time; in high-stress situations, one is apt to see things differently than they are." (Johnson 2017, 179)

This objection also seems to get the wrong extension in that it applies to much more than exorcism. We can grant that high-stress situations do lessen the reliability of our processes at some margin, but this is not 
to say that high-stress situations make these processes overall unreliable. Moreover, the objection assumes that exorcisms are typically high-stress situations, but this is not entirely obvious. Exorcisms often take several sessions drawn out over days, weeks, or months, which perhaps indicates that the exorcist is not always highly stressed.

(d) "Catholic exorcists... already believe in demons and likely that the subject is possessed." (Johnson 2017, 179)

This objection again has the wrong extension-a young chemist already believes in atoms and electrons before conducting her experiment, but this surely does not defeat her belief that atoms and electrons exist, or her belief that atoms and electrons are involved in the best explanation of the experiment's results. Moreover, the objection is empirically unsubstantiated in that in practice exorcists do not exorcise the vast majority of those seeking exorcism (Amorth 1990; Mariani 2018; Giordan and Possamai 2018), who are accounted for by exorcists themselves as cases of fraud or mental illness. Plausibly, cognitive states such as our beliefs can affect our sensory and other epistemic processes (Silins 2016), but this is not to say that they make these processes less reliable or overall unreliable, or that there is a problem particularly germane to exorcism here.

(e) Many cases of apparent possession and exorcism do turn out to be cases of fraud or mental illness, and this defeats the exorcist's beliefs about any token case, even if demons really do explain some cases. One problem with this objection is that we do not have (and perhaps cannot acquire) reliable statistics about what proportion of cases of apparent possession and exorcism turn out to be cases of fraud and mental illness, but let us grant that it is a large proportion. There are nevertheless processes that an exorcist can engage in to help minimize this defeater, such as checking the background and medical history of the person requesting an exorcism. As noted, the vast majority of people who present themselves to exorcists complaining of possession do not end up being exorcised. In a case in which the background and medical history of a person requesting an exorcism has not been checked, the exorcist likely should not treat a belief that testimony is offered by a demon as resulting from a reliable process. But the fact that a process is known to be unreliable under certain conditions is not an argument against its reliability in general.

By analogy, suppose that we know that some medical test for rare disease $Y$ has a high rate of false positives among those who in fact have the quite common disease $Z$, and an unknown rate of false positives for those who do not have disease $Z$. When applying the medical test for disease $Y$ without having first tested for disease $Z$, there is reason to think that the process 
of testing for disease $\mathrm{Y}$ is an unreliable one under that condition. This defeats justification for the belief that the patient has disease $Y$ in the event of a positive result. But if those suffering from disease $Z$ have been screened out, there is no longer evidence that the process of testing for disease $Y$ will be an unreliable one, and so no defeater is present in such cases. In the case of exorcism, one cannot ever be sure that every case of fraud and mental illness ("disease Z") has been screened out. Although this shows that the exorcist is not justified in treating his testifier-identification as infallible, it does not show that the exorcist's process of testifier-identification is unreliable post-screening. Again, when a medic wishes to conduct the test for disease $\mathrm{Y}$ it would be wise to conduct the test for disease $\mathrm{Z}$ first, but they need not have knowledge that their test for disease $\mathrm{Z}$ itself suffers from no false negatives whatsoever in order to be free from a defeater in their beliefs about whether the patient suffers from disease Y. This understanding of why checking the background and medical history of the person presenting for exorcism is epistemically important offers an alternative to Johnson's claim that:

The Catholic Church, for example, will take the fact that their priests can't find a natural explanation for a supposed possession as good reason to conclude that a demon is the cause. But this involves a variety of the appealing to ignorance fallacy that I call the "mystery therefore magic" fallacy. (Johnson 2017, 179)

(f) There are plausible philosophical arguments against the existence of demons.

So far as I am aware, the main (implicit, rarely elaborated) philosophical argument against the existence of demons seems to be a general appeal to naturalism. One might also argue that the existence of demons, or the claim that demons can possess human beings, is incompatible with God's omnibenevolence. These are both questionable arguments on their face but, more importantly, that there are plausible philosophical arguments against the existence of $\mathrm{X}$ does not seem to act as a defeater for one's beliefs involving X. For instance, that plausible philosophical arguments for moral anti-realism can be mustered does not seem to act as a defeater for one's belief that murder is morally wrong. Plausibly, very powerful philosophical arguments for moral anti-realism and a complete dearth of arguments for moral realism might act as a defeater for one's belief that murder is morally wrong, but this is not the situation that we face with respect to moral beliefs or with respect to beliefs about the existence of demons 
(g) We have no good metaphysical account of what it means for someone to be possessed and the idea seems to raise philosophical problems. It seems that we lack a good account of the metaphysics of possessionthough see (S. Guthrie 2018)-or how to resolve the problems it seems to pose for the philosophy of mind: would possession require adherence to a particular view of the mind-body relationship?, how is it that the demonic mind comes to interact with the body of the possessed?, what happens to the mind of the possessed during this period?, should we find physical changes in the brain of the possessed on which the demonic mind supervenes? That a phenomena does not have a neat metaphysical description and that it raises philosophical problems does not seem to act as a defeater for one's belief that it occurs-we do not have a good (or, widely agreed upon) metaphysical account of how mind arises in the ordinary case, and all such accounts raise philosophical problems of one kind or another, but it would be strange to conclude that this undermines our everyday beliefs about minds.

In answering the potential defeaters to be found in Johnson's paper and other plausible potential defeaters, I have given an inductive case for (3).

\section{CONCLUSION}

In many cases of exorcism, the exorcist may treat as reliable the process by which he comes to believe that testimony is offered by a demon. In turn, the exorcist may make.

I end by demarcating three things that the argument offered here does not show. First, it does not justify belief in the other sorts of phenomena that Johnson notes are sometimes attributed to demons, such as hauntings, since in these cases there is no belief that one is offered testimony by a demon. I take this to be a positive feature of the argument, which begins to make good on the desiderata that possession and exorcism be distinguished from superstition (Coleman 2018). Second, it does not show that belief in phenomena like demonic infestation, oppression, or obsession is justified, since in these cases there is not typically a belief that one is offered testimony by a demon. Third, it does not by itself justify the ordinary member of the public in believing that exorcists are sometimes offered testimony by demons or that demons exist-to comment on this we would have to further investigate the conditions under which testimony about the occurrence of supernatural or extraordinary events may be believed, a topic voluminously discussed elsewhere (McGrew 2019; Corner 2005). 


\section{BIBLIOGRAPHY}

Amorth, Gabriele. 1990. An Exorcist Tells His Story. San Francisco: Ignatius Press.

Antoni, Andrea De. 2017. "Sympathy from the Devil: Experiences, Movement and Affective Correspondences during a Roman Catholic Exorcism in Contemporary Italy." fapanese Review of Cultural Anthropology 18 (1): 143-57. https://doi.org/10.14890/jrca.18.1_143.

Aquinas, Thomas. 1947. Summa Theologica. Translated by English Province Dominicans. New York: Bezinger Bros.

Boyd, Gregory. 2001. Satan and the Problem of Evil. Westmont, IL: InterVarsity Press.

Coleman, Gerald D. 2018. "Separating Exorcism from Superstition." The National Catholic Bioethics Quarterly 18 (4): 595-602. https://doi.org/10.5840/ncbq201818463.

Corner, David. 2005. "Miracles." Internet Encyclopedia of Philosophy. 2005. https://www. iep.utm.edu/miracles/.

Dunnington, Kent. 2018. "The Problem with the Satan Hypothesis: Natural Evil and Fallen Angel Theodicies." Sophia 57 (2): 265-74. https://doi.org/10.1007/s11841-017-0608-7.

Dwyer, Graham. 1999. "Healing and the Transformation of Self in Exorcism at a Hindu Shrine in Rajasthan.” Social Analysis 43 (2): 108-37.

Gillig, Paulette Marie. 2009. "Dissociative Identity Disorder: A Controversial Diagnosis." Psychiatry 6 (3): 24-9.

Giordan, Giuseppe, and Adam Possamai. 2018. "Mastering the Devil: A Sociological Analysis of the Practice of a Catholic Exorcist." Current Sociology 66 (1): 74-91. https://doi. org/10.1177/0011392116686817.

Guthrie, Elspeth, Seri Abraham, and Shahzada Nawaz. 2016. "Process of Determining the Value of Belief About Jinn Possession and Whether or Not They Are a Result of Mental Illness." British Medical fournal Case Reports. https://doi.org/10.1136/bcr-2015-214005.

Guthrie, Shandon. 2018. Gods of This World: A Philosophical Discussion and Defense of Christian Demonology. Eugene, OR: Pickwick Publications.

Helton, Grace. 2016. "Recent Issues in High-level Perception." Philosophy Compass 11 (12): 851-62. https://doi.org/10.1111/phc3.12383.

Johnson, David Kyle. 2017. "Justified Belief in the Existence of Demons Is Impossible." In Philosophical Approaches to Demonology, 175-91. New York: Routledge.

Kroll, Jerome, and Bernard Bachrach. 1984. "Sin and Mental Illness in the Middle Ages." Psychological Medicine 14 (3): 507-14. https://doi.org/10.1017/S0033291700015105.

Lobach, Eva, and Dick J Bierman. 2004. "The Invisible Gaze: Three Attempts to Replicate Sheldrake's Staring Effects." Proceedings of 47th Parapsychology Association Annual Convention, 77-90.

Lopez, Donald. 1996. Elaborations on Emptiness: Uses of the Heart Sutra. Princeton, NJ: Princeton University Press.

Mariani, Mike. 2018. “American Exorcism.” The Atlantic, December 2018. https://www. theatlantic.com/magazine/archive/2018/12/catholic-exorcisms-on-the-rise/573943/.

Martin, Malachi. 1992. Hostage to the Devil: The Possession and Exorcism of Five Contemporary Americans. 2nd Ed. San Francisco: Harper.

McGrew, Timothy. 2019. “Miracles.” Stanford Encyclopedia of Philosophy. 2019. https:// plato.stanford.edu/entries/miracles/.

Rogo, Scott. 1974. "Demonic Possession and Parapsychology." Parapsychology Review 5 (6): $18-24$.

Shafer-Landau, Russ. 2012. "Evolutionary Debunking, Moral Realism and Moral Knowledge." Journal of Ethics and Social Philosophy 7 (1): 1-38. https://doi.org/10.26556/jesp.v7i1.68.

Shieber, Joseph. 2015. Testimony: A Philosophical Introduction. New York: Routledge. 
Silins, Nicholas. 2016. "Cognitive Penetration and the Epistemology of Perception." Philosophy Compass 11 (1): 24-42. https://doi.org/10.1111/phc3.12292.

Utz, Aisha. 2012. "Conceptualizations of Mental Health, Illness, and Healing." In Counseling Muslims: Handbook of Mental Health Issues and Interventions, edited by Sameera Ahmed and Mona M. Amer, 15-32. New York: Taylor \& Francis.

Weller, Philip T., trans. 2017. The Roman Ritual, Volume 2. Caritas Publishing. 